\title{
Ergonomic Evaluation of Work Related Musculoskeletal Disorders and Postural Stress among Male Potato Cultivators of West Bengal, India
}

\begin{abstract}
:
Background: Apart from cereal production (rice, wheat, etc.) agricultural labourers are engaged in vegetable cultivation in West Bengal, India. Potato cultivation is one of the important vegetable cultivation in India. The potato cultivation tasks are repetitive in nature and those are carried out mainly by manual efforts. Most of the tasks of potato cultivation are monotonous, strenuous, physiologically demanding as well as time-consuming. Objective: The present study was aimed to evaluate musculoskeletal disorders (MSDs) and postural stress among male workers engaged in different potato cultivation jobs. Methods: The study was conducted on 163 male potato cultivators in different districts of West Bengal state. A modified Nordic Questionnaire and Body Part Discomfort scale were applied to identify MSDs in different body parts. The postural pattern was assessed by direct observation method. The postural stress was analyzed by OWAS, REBA and QEC methods. Result: The results show that the prevalence of MSDs was very high among the workers and the most affected areas were back and upper extremity. Postural analysis indicated that the subjects had to adopt different stressful postures during performing different potato cultivation jobs. During potato harvesting operation the workers were subjected to greater postural stress than that of other tasks. Conclusion: Postural stress might be the reason of the occurrence of MSDs. From this study it has been recommended that workers should avoid bad work postures as far as possible during work for reducing job related health hazards.
\end{abstract}

Key Words: MSDs, Work Posture, Posture Analysis, Work Experience, Potato Cultivation Jobs
Agricultural work is the most primitive type of employment in the world. India is an agricultural-based country and agriculture plays an important role in the economic development of India. A census conducted in 2011 in India highlighted that $58.4 \%$ of the total population in the country are engaged in agricultural work [1]. According to the Census report [1] it has been found that in West Bengal state about $43.35 \%$ of male and $46.3 \%$ of the female population are engaged in agricultural work. (East and West), Bankura, Purulia, Howrah district etc. are engaged in agriculture throughout the year. Most of these workers, those are involved in agricultural works are coming from rural and economically backward areas where employment opportunities are limited. Because of their poverty, farmers are obliged to undertake most agricultural tasks relying solely on their own efforts. Even today, Indian agriculture depends to a very large extent on manual labour, although modernization has reached

\section{Introduction}

A large number of people of this state, especially of Midnapore

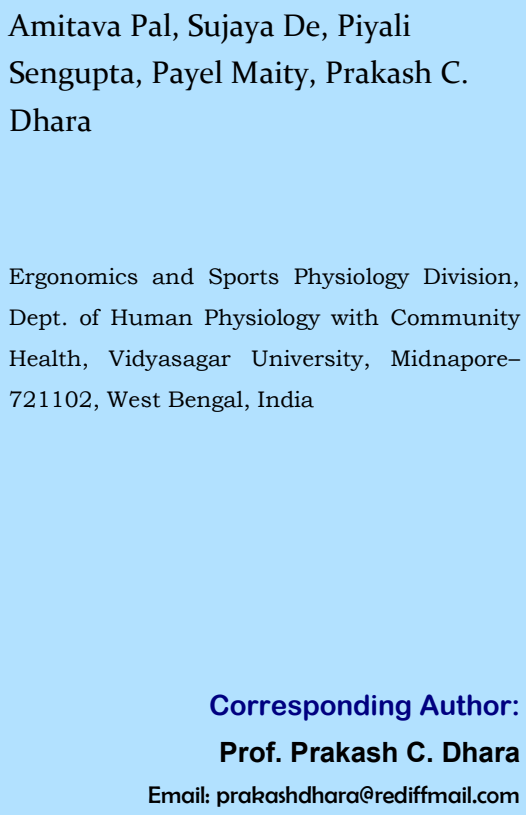

Corresponding Author:

Prof. Prakash C. Dhara Email: prakashdhara@rediffmail.com

some parts of the subcontinent. Though the agricultural workforce is by far the major work forcing the third world countries, its work organization has not received much attention.

Apart from cereal production (rice, wheat, etc.) agricultural labourers are engaged in vegetable cultivation. Potato cultivation is one of the important vegetable cultivation in India. Both male and female workers are involved in this job and expend a great extent of their physiological cost. The potato cultivation is a seasonal work. The potato is cultivated in one season (NovemberMarch). Potato cultivation totally depends upon irrigation from rivers, canals and underground water. There are different tasks in potato cultivation, which are performed in different phase viz., plantation of potato, tunneling and harvesting of potato. Prior to potato cultivation, weeding is done to remove unwanted weeds. After this the land surface is level. Then potato seeds (cut pieces of potato) are sown in rows by making a shallow dig with the hand. During sowing a regular distance is maintained. The seeds are covered with soil. The seeds are sown in several 
rows, keeping some gaps $(40-45 \mathrm{~cm})$ between two rows. For this activity, agricultural workers adopt a very awkward posture for a prolonged time. After germination when the saplings are grown tunnels are made in the gap between two rows with the help of a small sized spade. These tunnels are used for irrigation purpose. Such tunnels are re-made after every phase of irrigation. Spading is another very strenuous activity whereby the workers have to work in a constantly bent posture. After a few months when the crop is fully grown under the ground, harvesting activities begin. The soil along the rows of plants is dug by the help of a spade. Care is taken to avoid the cutting of potato under the soil. Once the soil beneath the plants become loosens the potatoes are collected by the hand. The collected potatoes are kept in a sac or a basket. The potato cultivation tasks are repetitive in nature and those are carried out mainly by manual efforts. Most of the tasks of potato cultivation performed by the cultivators are monotonous, strenuous, physiologically demanding as well as time-consuming [2-3]. They have to face many job related health problems during work. Agricultural works are executed by manual labour and perhaps more than any other occupational group; agricultural workers are exposed to a tremendous variety of postural stress [4]. These manual operations may be physically demanding through postural requirements and are commonly regarded as a source of the drudgery that is potentially harmful to their health and well being. They may therefore be considered to be suitable for ergonomics intervention.

In labour intensive countries like India, few studies were done on agricultural workers. Das and Gangopadhyay [5] studied on posture related discomfort and occupational health problems among rice cultivators. Kar et al. [6] studied on work-rest patterns and work component of different rice cultivation tasks. Nag et al. [7] studied on drudgery, accidents and injuries in Indian agricultural worker. Kar and Dhara [8] studied on musculoskeletal disorders and socioeconomic status of farmers in West Bengal. Goswami et al. [9] studies on the work related musculoskeletal disorder and postural stress among female cultivators engaged in post harvesting tasks in India. However, studies on vegetable cultivation tasks, particularly in potato cultivation are scanty. Therefore, an ergonomic study was undertaken to assess the occupational health hazards of the male potato cultivators. Efforts have been made to evaluate different musculoskeletal disorders and postural stress of male workers during performing different tasks on potato cultivation job.

\section{Methods}

Site and subject : The study was conducted on 163 male workers having the age group of 18-50 years. Ethical approval and prior permission were obtained from the Institutional Ethics Committee before commencement of the study and the experiment was performed in accordance with the ethical standards of the committee and with the Helsinki Declaration. Prior to the experimental trial, the protocol was explained verbally in local language (Bengali) and informed consent was obtained from the subjects during field visits and the available adult males were randomly selected as subjects from different districts of West Bengal state, India. During field visits, complete information on the experience of the work of the workers was noted on the basis of a questionnaire. According to the nature of work performed by the workers, potato cultivation jobs were divided into the three tasks, viz. potato plantation, tunneling and potato harvesting.

Physical Parameters: Anthropometric measurements were taken from the subjects following standard technique and appropriate landmarks[10]. Height was measured to the nearest $0.1 \mathrm{~cm}$ using anthropometer (Hindustan Minerals) and weight to the nearest $0.1 \mathrm{~kg}$ using a portable weighing machine (Libra). From measures of height and weight of the subjects the body mass index (BMI) was computed using the following standard equation: $\mathrm{BMI}=$ weight $(\mathrm{kg}) /$ height $\left(\mathrm{m}^{2}\right)$.

Evaluation of Work Rest Patterns: The work-rest patterns of potato cultivators was determined by directly observing their work as well as by taking interview of the workers [11]. The work -rest cycle of different tasks of potato cultivation was studied by noting the actual work time and rest time. The total work shift was divided into work cycle and rest cycle. The rest period is the sum of prescribed rest pause (rest for food break) and job related rest pause (rest taken by the worker for self requirement during working hour). The actual work time was calculated by subtracting the actual rest pause from total work time. It was recorded carefully from beginning to end of the work by direct observation employing videography of the job. For this purpose, whole day works of the workers were video recorded in DVD mode and analyzed by using the software Xing MPEG player (Version 3.30). After a careful and repeated observation, the whole day work was evaluated and the duration of work time and different rest pauses of the workers were noted.

Determination of Postural Pattern: For evaluating the postural stresses, the postural pattern of the workers during performing their jobs was studied. The analysis of posture at different phases of potato cultivation jobs was made by the direct observation method employing video-photography [11]. The work posture of each subject was studied for each type of job for a whole working period. The postural change during performing the work was noted carefully and the time for adopting each posture was recorded. The observation was made by employing one subject one day strategy.

Musculoskeletal Disorder: The musculoskeletal disorders of the workers were evaluated by the modified Nordic questionnaire technique [12]. The questionnaire emphasized their individual details, type of work and the occurrence or frequency of pain felt in different parts of their body.

Discomfort Rating: The intensity of pain or different types of discomfort was evaluated by utilizing the body part discomfort (BPD) scale [13]. The scale consisted of marks from 1 to 10 and ranges from just noticeable discomfort to intolerable discomfort. A ' 0 ' in the scale meant no discomfort at all and ' 10 ' in the scale indicated intolerable discomfort. The mean value of scores (perceived rating of discomfort) of all segments was taken as the overall discomfort rating of the workers. 
Postural Analysis: The postures adopted by the workers in their working place depends upon the type of work, personal characteristics, the tools required to perform the particular work and also the duration and frequency of the work cycle. Postural analysis can be a powerful technique for assessing work activities as the risk of musculoskeletal injury associated with the posture [14]. So, various techniques have been applied for postural analyses to identify the stress of different phases of work. Working postures were evaluated by using OWAS (OVAKO Working postures Analysis System) method [15]. Although the OWAS method has a wide range of use, but the results can be low in detail [16]. Therefore, the REBA (Rapid Entire Body Assessment) method [16] and QEC (Quick Exposure Check) method [17] were also applied for analysis of work postures of the workers.

Statistical Analysis: Data were analyzed using STATISTICA (Vr. 6.0) for windows. Results for the general information items here expressed as mean $\pm S D$. Among the different groups of parameters ' $t$ '-test had also been made. The chi - square test was used for comparison of categorical variables.

\section{Results}

The physical characteristics of the workers have been shown in Table I. Nutritional status of the subjects was assessed from their BMI value and it was found that the mean value of BMI of subjects was within the normal range.

Before follow-up, complete information on the experience of the work of the workers was noted on the basis of a questionnaire and the subjects were divided into three groups based on their work experiences viz., Gr. -A (work experience $\leq 5$ years); Gr. -B (work experience 6-15 years) and Gr. -C (work experience $>15$ years). From the results it was revealed that about $14.72 \%$ workers had their work experiences for $\leq 5$ years, $54.60 \%$ workers had their work experiences for 6 to 15 years and $30.68 \%$ workers had experience of at least 16 years.

Table I The physical characteristics of the male cultivators

\begin{tabular}{|ccc|}
\hline Parameters & Mean \pm SD & Range \\
\hline Age $(\mathrm{yrs})$ & $33.24 \pm 10.33$ & $18-50$ \\
\hline Height $(\mathrm{Cm})$ & $162.06 \pm 5.35$ & $145.7-75.0$ \\
\hline Weight $(\mathrm{Kg})$ & $53.36 \pm 7.77$ & $39.6-77.4$ \\
\hline BMI $\left(\mathrm{Kg} / \mathrm{m}^{2}\right)$ & $20.28 \pm 2.49$ & $15.9-28.21$ \\
\hline Work Experience $(\mathrm{yrs})$ & $12.04 \pm 9.18$ & $1-37$ \\
\hline
\end{tabular}

The work-rest patterns of the potato cultivators were studied and have been presented in Table II. The workers started work by 7 a.m. and continued the work for about two hours. After this, they took a breakfast break for about 20 to 40 minutes. They would resume the work after this break and continue the work for about 2 to $2 \frac{1}{2}$ hours. Then they used to take another meal break (lunch) for a longer duration than the former break. It would continue for about $1 \frac{1}{2}$ to 2 hours. During this break they would also take a bath and rest for some time. After this break they had to start work from 2.30 p.m., which would continue for 3 hours.
From the observed results it was revealed that the work rest patterns were found to vary in different tasks of potato cultivation. The work time varied from $67.38 \%$ to $68.77 \%$ of the total work shift and rest time varied from $31.23 \%$ to $32.62 \%$ of the total work shift in different tasks of potato cultivation. The rest period of the cultivators included the food break. The results also indicate that the total work shift was significantly $(p<0.05)$ higher in potato harvesting operation than potato plantation and tunneling jobs. The total work period was also significantly $(p<0.05)$ higher in potato harvesting operation than the tunneling job. It was noted that the total working hours of the all groups of workers were approximately 9 hours including rest pause.

Table II: Mean \pm SD of work time and rest time $(\mathrm{min})$ of the cultivators in different potato cultivation tasks (The figures in the parentheses indicate the percentage of total time)

\begin{tabular}{|cccc|}
\hline $\begin{array}{c}\text { Different potato } \\
\text { cultivation jobs }\end{array}$ & $\begin{array}{c}\text { Total work } \\
\text { time }(\mathrm{min})\end{array}$ & $\begin{array}{c}\text { Total rest time } \\
(\mathrm{min})\end{array}$ & $\begin{array}{c}\text { Total duration of } \\
\text { work shift }(\mathrm{min})\end{array}$ \\
\hline Plantation $(\mathrm{n}=19)$ & $\begin{array}{c}380.74 \pm 28.98 \\
(68.77 \%)\end{array}$ & $\begin{array}{c}172.87 \pm 11.67 \\
(31.23 \%)\end{array}$ & $553.60 \pm 30.71^{*}$ \\
\hline Tunneling $(\mathrm{n}=22)$ & $\begin{array}{c}373.12 \pm 25.25 * \\
(67.38 \%)\end{array}$ & $\begin{array}{c}180.60 \pm 13.70 \\
(32.62 \%)\end{array}$ & $553.73 \pm 29.93^{*}$ \\
\hline $\begin{array}{c}\text { Potato Harvesting } \\
(n=20)\end{array}$ & $\begin{array}{c}391.68 \pm 25.90 \\
(67.79 \%)\end{array}$ & $\begin{array}{c}186.06 \pm 14.27 \\
(32.21 \%)\end{array}$ & $577.74 \pm 32.91$ \\
\hline All categories & $\begin{array}{c}380.87 \pm 27.31 \\
(67.96 \%)\end{array}$ & $\begin{array}{c}179.56 \pm 14.01 \\
(32.04 \%)\end{array}$ & $560.43 \pm 32.38$ \\
\hline
\end{tabular}

w.r.t Potato harvesting * $p<0.05$

The direct observation method was used for the analysis of postural patterns and results are shown in Table III. It was noted from the results that the workers had to adopt forward bending posture throughout the work time. The workers were found to twist and bend their body frequently during potato plantation and potato harvesting jobs. They had also to adopt forward bending posture for about $89.31 \%$ of the work-time in case of tunneling job and it were about $51.53 \%$ and about $56.54 \%$ in case of plantation and potato harvesting jobs respectively. The workers engaged in potato plantation and potato harvesting jobs were compelled to adopt squat sitting posture for about $39.17 \%$ and $34.25 \%$ of the work-time respectively.

According to the nature of work performed by workers, the potato cultivation jobs were divided into the three tasks, viz. potato plantation, tunneling and potato harvesting, which already mansion earlier. The prevalence of MSDs of three categories of working groups was studied and compared between the categories and showed in Table IV. The results indicated that the occurrence of MSDs was significantly different in different sites of the body between the workers engaged in different jobs of potato cultivation (potato plantation, tunneling and potato harvesting jobs). The workers engaged in tunneling activities had significantly higher percentage of MSDs in the shoulder $(p<0.001)$, upper back $(p<0.001)$ and lower back $(p<0.05)$ than the workers engaged in potato plantation. In addition to those workers engaged in tunneling activities also had a higher percentage of 
other segmental discomfort than those of potato plantation workers excepting wrist, knee and feet. From the results it was revealed that the workers engaged in potato harvesting had significantly higher percentage of MSD in the shoulder $(p<0.01)$, upper back $(p<0.01)$ and lower back $(p<0.05)$ than the workers engaged in potato plantation. In addition to those workers engaged in potato harvesting activities also had a higher percentage of other segmental discomfort than those of potato plantation workers excepting elbow and wrist. Whereas, potato harvesting workers had significantly lower prevalence of MSD in elbow $(p<0.001)$ than the potato planting workers. The results also indicated that potato harvesting workers had significantly higher percentage of discomfort in the knee $(p<0.05)$ and feet $(p<0.01)$ compared to the workers engaged in tunneling activities.

Table III: Mean \pm SD and percentage (\%) of time (min) for adopting different postures in a work shift by the cultivators during performing different potato cultivation jobs.

\begin{tabular}{|c|c|c|c|}
\hline \multirow{2}{*}{$\begin{array}{l}\text { Different working } \\
\text { posture }\end{array}$} & \multicolumn{3}{|c|}{ Different potato cultivation tasks } \\
\hline & $\begin{array}{l}\text { Plantation } \\
(n=19)\end{array}$ & $\begin{array}{l}\text { Tunneling } \\
(n=22)\end{array}$ & $\begin{array}{l}\text { Potato Harvesting } \\
\qquad(\mathrm{n}=20)\end{array}$ \\
\hline Sitting (squatting) & $\begin{array}{c}149.12 \pm 49.36 \\
(39.17 \%)\end{array}$ & - & $\begin{array}{c}134.15 \pm 51.66 \\
(34.25 \%)\end{array}$ \\
\hline Forward bends & $\begin{array}{c}196.19 \pm 60.95^{*} \\
(51.53 \%)\end{array}$ & $\begin{array}{c}333.22 \pm 22.84 \\
(89.31 \%)\end{array}$ & $\begin{array}{c}221.47 \pm 48.28^{*} \\
(56.54 \%)\end{array}$ \\
\hline Walking & $\begin{array}{c}35.43 \pm 12.44 \\
(9.31 \%)\end{array}$ & $\begin{array}{c}39.90 \pm 14.25 \\
(10.69 \%)\end{array}$ & $\begin{array}{c}36.06 \pm 10.60 \\
(9.21 \%)\end{array}$ \\
\hline $\begin{array}{l}\text { Total working } \\
\text { period }\end{array}$ & $380.74 \pm 28.98$ & $373.12 \pm 25.25$ & $391.68 \pm 25.9$ \\
\hline
\end{tabular}

w.r.t Tunneling * $p<0.001$

Table IV: Comparison of MSDs of male workers between different groups of potato cultivation.

\begin{tabular}{|cccc|}
\hline Body Segment & $\begin{array}{c}\text { Plantation } \\
(\mathbf{n}=51)\end{array}$ & $\begin{array}{c}\text { Tunneling } \\
(\mathbf{n}=60)\end{array}$ & $\begin{array}{c}\text { Harvesting } \\
(\mathbf{n}=52)\end{array}$ \\
\hline Neck & $13(25.49)$ & $22(36.67)$ & $22(42.31)$ \\
\hline Shoulder & $12(23.53)$ & $38(63.33)^{* * *}$ & $27(51.92)^{* *}$ \\
\hline Elbow & $24(47.06)$ & $37(61.67)$ & $15(28.85) \# \# \#$ \\
\hline Wrist & $34(66.67)$ & $30(50.00)$ & $34(65.38)$ \\
\hline Upper Back & $21(41.18)$ & $45(75.00)^{* * *}$ & $38(73.08)^{* *}$ \\
\hline Lower Back & $43(84.31)$ & $58(96.67)^{*}$ & $51(98.08)^{*}$ \\
\hline Hip & $19(37.25)$ & $29(48.33)$ & $24(46.15)$ \\
\hline Knee & $16(31.37)$ & $11(18.33)$ & $16(34.62) \#$ \\
\hline Feet & $10(19.61)$ & $5(8.33)$ & $16.77) \# \#$ \\
\hline
\end{tabular}

w.r.t. Plantation $* \mathrm{p}<0.05, * * \mathrm{p}<0.01, * * * \mathrm{p}<0.001$ w.r.t. Tunneling \# $p<0.05, \# p<0.01, \# \# p<0.001$

The occurrence of MSDs in different experience groups had also been studied and a comparison was done in MSDs among differ- -ent experience groups and presented in Table V. Gr.-A (work experience $\leq 5$ years) had significantly higher percentage of MSDs in the shoulder $(p<0.001)$, elbow $(p<0.05)$, upper back $(p<0.05)$, hip $(p<0.001)$ and feet $(p<0.05)$ than Gr. B workers (work experience 6-15 years) and significantly higher percentage of MSDs in shoulder $(p<0.01)$ and hip $(p<0.05)$ than Gr. C workers (work experience $>15$ years) respectively. Gr. C workers have significantly $(p<0.05)$ higher prevalence of discomfort in the shoulder than $\mathrm{Gr}$. B workers.

Table V: Prevalence of MSD of male workers on the basis of their work experiences (the values in parenthesis indicate the percentage of MSD).

\begin{tabular}{|c|c|c|c|}
\hline Body segment & $\begin{array}{c}\text { Gr-A ( } \leq 5 \text { yrs.) } \\
(n=24) \\
f(\%)\end{array}$ & $\begin{array}{c}\text { Gr-B (6-15 yrs.) } \\
(n=89) \\
f(\%)\end{array}$ & $\begin{array}{c}\text { Gr-C (>15 yrs.) } \\
(n=50) \\
f(\%)\end{array}$ \\
\hline Neck & $11(45.83)$ & $28(31.46)$ & $18(36.0)$ \\
\hline Shoulder & $21(87.5)$ & $30(33.71)^{* * *}$ & $26(52.0)^{* * \#}$ \\
\hline Elbow & $16(66.66)$ & $36(40.45)^{*}$ & $24(48.0)$ \\
\hline Wrist & $17(70.83)$ & $51(57.30)$ & $30(60.0)$ \\
\hline Upper Back & $19(79.16)$ & $50(56.18)^{*}$ & $35(70.0)$ \\
\hline Lower Back & $24(100.0)$ & $80(89.88)$ & $48(96.0)$ \\
\hline Hip & $18(75.0)$ & $30(33.71)^{* * *}$ & $24(48.0)^{*}$ \\
\hline Knee & $10(41.66)$ & $20(22.47)$ & $15(30.0)$ \\
\hline Feet & $8(33.33)$ & $13(14.61)^{*}$ & $10(20.0)$ \\
\hline
\end{tabular}

The quantitative assessment of the discomfort of the workers engaged in different potato cultivation jobs had also been done. The perceived rating of discomfort of the workers was studied by using a 10-point scale which was graded from Grade 0 (no pain) to Grade 10 (very severe pain). According to the degree of severity, the scores of the 10-point scale were divided into three subgroups, i.e., mild (1-4), severe (>4-7) and very severe (>7). The results showed that the workers engaged in different phases of potato cultivation tasks were reported to suffer from different degrees of perceived exertion. It was revealed that severe degree of discomfort ( $>4$ to $\leq 7$ ) was observed in lower back among the cultivators of all potato cultivation tasks (Table VI). The comparison between the work groups showed that the tunneling workers had a significantly higher degree of pain at shoulder $(p<0.001)$, upper arm $(p<0.001)$ and upper back $(p<0.05)$ region than that of the plantation workers and had a significantly higher degree of pain at upper arm $(p<0.05)$ than that of the harvesting workers. The harvesting workers had a significantly higher degree of pain at shoulder $(p<0.01)$, upper back $(p<0.01)$ and middle back $(p<0.001)$ region than that of the plantation workers and had a significantly higher degree of pain in middle back $(p<0.01)$, calf (right $p<0.05$ ) and feet (right $p<0.05$; left $p<0.01$ ) than that of the tunneling workers. 
Table VI: The perceived rate of discomfort (Mean \pm SD) in different body segments of potato cultivators during performing different potato cultivation jobs .

\begin{tabular}{|c|c|c|c|}
\hline Body Segment & Plantation & Tunneling & Harvesting \\
\hline Neck & $1.37 \pm 2.49$ & $2.13 \pm 2.98$ & $2.40 \pm 3.04$ \\
\hline \multirow{2}{*}{ Shoulder } & $1.27 \pm 2.36$ & $3.58 \pm 3.0^{\# \# \# ~}$ & $2.67 \pm 2.95^{\# \#}$ \\
\hline & $1.25 \pm 2.27$ & 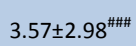 & $2.67 \pm 2.98^{\# \#}$ \\
\hline \multirow{2}{*}{ Upper arm } & $1.43 \pm 2.47$ & $3.52 \pm 3.16^{\# \# \#}$ & $2.26 \pm 2.69^{\$}$ \\
\hline & $1.47 \pm 2.48$ & $3.62 \pm 3.09^{\# \# \#}$ & $2.30 \pm 2.77^{\$}$ \\
\hline \multirow{2}{*}{ Lower arm } & $3.33 \pm 2.36$ & $2.60 \pm 2.84$ & $3.50 \pm 2.9$ \\
\hline & $3.25 \pm 2.56$ & $2.68 \pm 2.95$ & $3.48 \pm 2.93$ \\
\hline Upper back & $2.67 \pm 3.29$ & $3.95 \pm 2.66^{\#}$ & $4.31 \pm 2.91^{\# \#}$ \\
\hline Middle back & $2.61 \pm 2.39$ & $3.32 \pm 2.11$ & $4.62 \pm 2.01^{\# \# \# \$ \$}$ \\
\hline Lower Back & $4.92 \pm 2.64$ & $5.37 \pm 2.0$ & $5.58 \pm 2.03$ \\
\hline Buttock & $3.18 \pm 2.34$ & $3.80 \pm 2.26$ & $3.42 \pm 3.01$ \\
\hline \multirow{2}{*}{ Thigh } & $1.84 \pm 2.58$ & $2.43 \pm 2.62$ & $2.19 \pm 2.47$ \\
\hline & $1.94 \pm 2.65$ & $2.37 \pm 2.57$ & $2.12 \pm 2.37$ \\
\hline \multirow{2}{*}{ Cuff } & $1.63 \pm 2.50$ & $0.83 \pm 1.8$ & $1.58 \pm 2.15^{\lessgtr}$ \\
\hline & $1.59 \pm 2.46$ & $0.80 \pm 1.73$ & $1.52 \pm 2.16$ \\
\hline \multirow{2}{*}{ Feet } & $0.96 \pm 2.01$ & $0.38 \pm 1.33$ & $1.17 \pm 1.84^{\$}$ \\
\hline & $0.98 \pm 2.05$ & $0.42 \pm 1.41$ & $1.33 \pm 2.06^{\$ \$}$ \\
\hline $\begin{array}{l}\text { Over all discomfor } \\
\text { rating of the body }\end{array}$ & $2.22 \pm 0.97$ & $2.67 \pm 1.18^{\#}$ & $2.69 \pm 2.53$ \\
\hline
\end{tabular}

w.r.t Plantation \# $\mathrm{p}<0.05$, \#\# $\mathrm{p}<0.01, \# \# \mathrm{p}<0.00$ w.r.t Tunneling $\$ p<0.05, \$ p<0.01$

A comparative study of reported mild, severe and very severe discomfort rating has been worked out and the results are presented in Table VII. The results reveal that percentages of workers expressed severe rating of discomfort were higher than that of mild rating in different segment of the body.

In the present study, different postures adopted by the cultivators while performing different tasks of potato cultivation were analyzed by three methods, viz., OWAS, REBA and QEC and represented in detail, along with the maximum discomfort zone and rating (Table VIII and Table IX). The dominant postures adopted by the workers during potato plantation were forward bending and squat sitting postures. From the results of postural assessment of potato plantation job by OWAS method, it was found that the forward bending posture needed corrective measure as soon as possible and squat sitting posture needed corrective measures in the near future. From the results of postural assessment by REBA method, it was noted that both forward bending and squat sitting posture of potato plantation job has been categorized as high risk and needed investigation and changes implemented. The analyses of potato plantation tasks using the QEC indicated the risk level to specific body parts including the shoulder/arm, wrist/hand, and neck (Table IX). From the results it was revealed that the risk level was high in back, wrist/hand and neck regions and moderate in shoulder/arm regions while adopting forward bending posture. While adopting squat sitting posture, the risk level was high in back and neck regions and moderate in shoulder/arm and wrist/hand regions.

Postures adopted in tunneling jobs were analyzed by three posture analysis methods. From the results of postural assessment of the tunneling job by OWAS method, it was found that the posture needed corrective measure as soon as possible. Similarly, from the results of postural assessment by REBA method, it was found that the posture for tunneling jobs has been categorized as very high risk. The results of the posture analysis by QEC method indicated that the risk levels were high in back and neck regions and moderate in the shoulder/arm as well as in wrist/ hand regions while performing tunneling task.

The postures adopted by the cultivators while harvesting potatoes were forward bending posture and squat sitting. From the results of postural assessment of the potato harvesting job by OWAS method, it was found that the both forward bending and squatting postures needed corrective measure as soon as possible. Similarly from the results of postural assessment by REBA

Table VII: Percentage distribution of individual according to severity of perceived rate of discomfort in different body segments during performing potato cultivation jobs.

\begin{tabular}{|c|c|c|c|c|}
\hline \multicolumn{2}{|c|}{ Body Segment } & Mild (1-4) & Sever $(>4-7)$ & Very Sever (>7) \\
\hline \multicolumn{2}{|l|}{ Neck } & 12.88 & 15.34 & 6.75 \\
\hline \multirow{2}{*}{ Shoulder } & $\mathrm{R}$ & 20.86 & 18.40 & 7.98 \\
\hline & L & 19.63 & 21.47 & 6.13 \\
\hline \multirow{2}{*}{ Upper arm } & $\mathrm{R}$ & 12.27 & 28.83 & 4.91 \\
\hline & L & 12.27 & 28.83 & 5.52 \\
\hline \multirow{2}{*}{ Lower arm } & $\mathrm{R}$ & 30.67 & 26.38 & 4.91 \\
\hline & L & 25.77 & 29.45 & 4.91 \\
\hline \multicolumn{2}{|l|}{ Upper back } & 18.40 & 37.42 & 7.98 \\
\hline \multicolumn{2}{|l|}{ Middle back } & 42.94 & 30.06 & 1.84 \\
\hline \multicolumn{2}{|l|}{ Lower Back } & 37.42 & 38.04 & 17.79 \\
\hline \multicolumn{2}{|l|}{ Buttock } & 34.97 & 31.29 & 5.52 \\
\hline \multirow{2}{*}{ Thigh } & $\mathrm{R}$ & 21.47 & 21.47 & 1.84 \\
\hline & L & 19.02 & 23.93 & 1.23 \\
\hline \multirow{2}{*}{ Cuff } & $\mathrm{R}$ & 13.50 & 14.72 & 0.00 \\
\hline & $\mathrm{L}$ & 13.50 & 12.88 & 0.61 \\
\hline \multirow{2}{*}{ Feet } & $R$ & 11.66 & 6.75 & 0.00 \\
\hline & L & 10.43 & 8.59 & 0.00 \\
\hline
\end{tabular}


Original Article / IJOSH/ ISSN 2091-0878

Table VIII: Results (action and risk levels) of postural analysis of the male potato cultivators in different potato cultivation tasks

\begin{tabular}{|c|c|c|c|c|c|c|c|}
\hline \multirow{2}{*}{\multicolumn{2}{|c|}{ Tasks }} & \multicolumn{2}{|r|}{ OWAS } & \multicolumn{2}{|r|}{ REBA } & \multirow{2}{*}{$\begin{array}{c}\text { Max. } \\
\text { discomfort } \\
\text { in body parts }\end{array}$} & \multirow[b]{2}{*}{$\begin{array}{l}\text { Maximum } \\
\text { Discomfort Rating }\end{array}$} \\
\hline & & $\begin{array}{l}\text { Action } \\
\text { Level }\end{array}$ & Risk level & Action Level & Risk level & & \\
\hline \multirow{2}{*}{ Plantation } & $\begin{array}{l}\text { Forward } \\
\text { bending }\end{array}$ & 3 & $\begin{array}{c}\text { Corrective measures as } \\
\text { soon as possible }\end{array}$ & 10 & $\begin{array}{l}\text { High risk, investigate and } \\
\text { implement change }\end{array}$ & \multirow{2}{*}{ Lower back } & 4.92 \\
\hline & Squatting & 2 & $\begin{array}{c}\text { Corrective measures in } \\
\text { the near future }\end{array}$ & 8 & $\begin{array}{l}\text { High risk, investigate and } \\
\text { implement change }\end{array}$ & & \pm 2.64 \\
\hline \multicolumn{2}{|c|}{ Tunneling } & 3 & $\begin{array}{c}\text { Corrective measures as } \\
\text { soon as possible }\end{array}$ & 11 & $\begin{array}{c}\text { Very high risk, implement } \\
\text { change }\end{array}$ & Lower back & $\begin{array}{r}5.37 \\
\pm 2.0 \\
\end{array}$ \\
\hline \multirow[b]{2}{*}{ Harvesting } & $\begin{array}{l}\text { Forward } \\
\text { bending }\end{array}$ & 3 & $\begin{array}{c}\text { Corrective measures as } \\
\text { soon as possible }\end{array}$ & 12 & $\begin{array}{c}\text { Very high risk, implement } \\
\text { change }\end{array}$ & \multirow[b]{2}{*}{ Lower back } & 5.58 \\
\hline & Squatting & 3 & $\begin{array}{c}\text { Corrective measures as } \\
\text { soon as possible }\end{array}$ & 11 & $\begin{array}{c}\text { Very high risk, implement } \\
\text { change }\end{array}$ & & \pm 2.03 \\
\hline
\end{tabular}

Table IX: Results (scores and risk level) of postural analysis by QEC method of the male potato cultivators in different potato cultivation tasks.

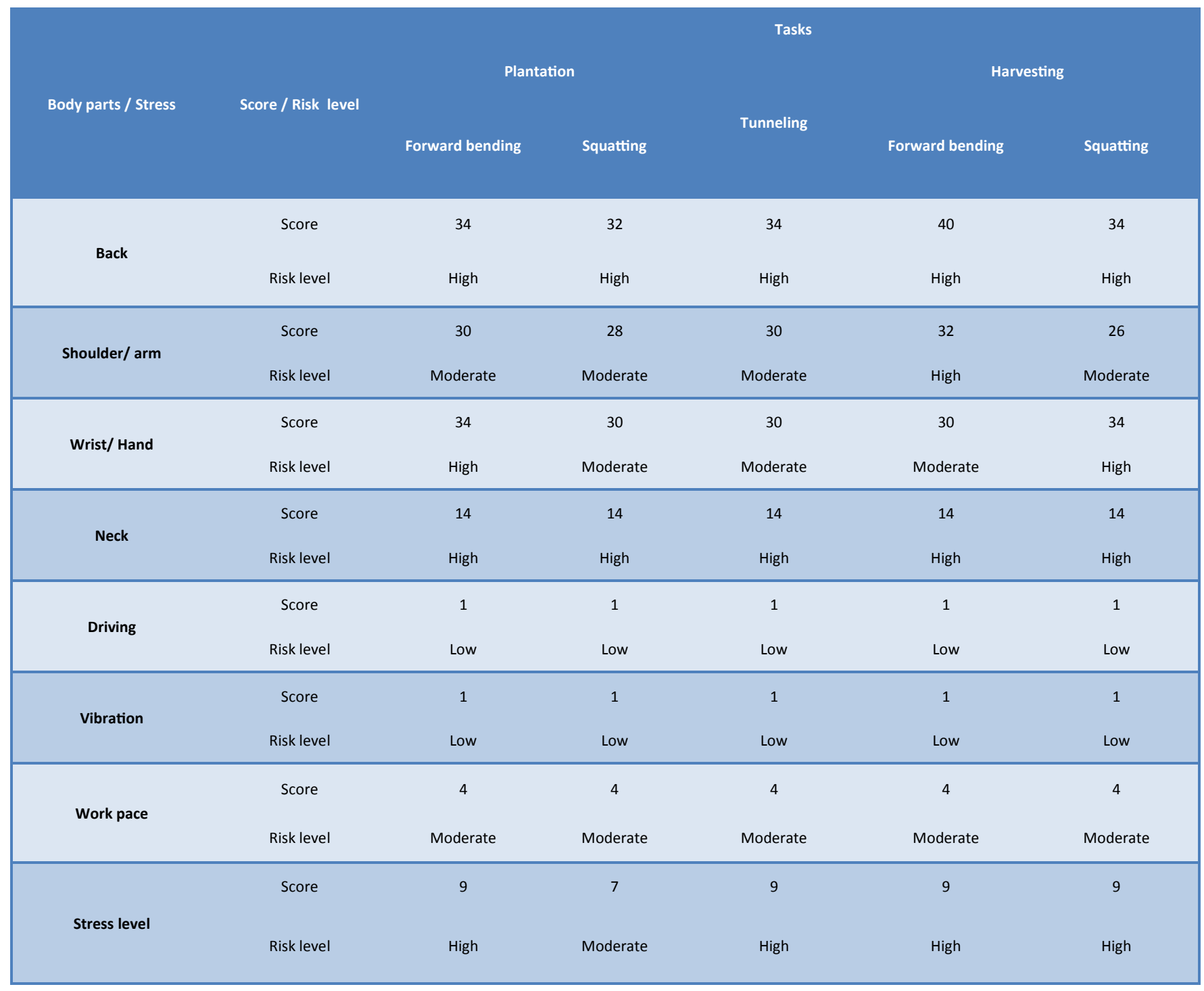


method, it was found that the both forward bending and squatting postures of potato harvesting have been categorized as very high risk. The results of the posture analysis by QEC method indicated that the risk levels were high in back, shoulder/arm and neck regions and moderate in the wrist/hand regions while performing potato harvesting job in forward bending posture. While performing potato harvesting job in squat sitting posture the risk levels were high in back, wrist/hand and neck regions and moderate in shoulder/arm regions.

\section{Discussion}

The workers were habituated in different awaked postures while performing different jobs of potato cultivation. The change of posture was a common factor during dynamic work and in long term working condition. The cultivators were compelled to adopt in different awkward postures for prolonged periods of time while performing different potato cultivation jobs. Although awkward postures were most prevalent in the jobs, it was also noted that there were a lot of non-ergonomic postures of certain parts of the body which may be the possible contributing causes of pain in different body segments. A good posture becomes even more important when forceful tasks are performed. Posture is as important for the performance of tasks as it is for promoting health and minimizing stress and discomfort during work [18]. Thus, assessment of work postures is one of the starting points to address the problem of work-related body pain. There are many practical methods for evaluating postural workload based on a postural classification [19-20]. The direct observation method was proved to be a good method for studying the work postures in agricultural and other work when involved in whole body work requiring moving. The validity of visual observation to assess posture in a laboratory-simulated material-handling task [21] was established. Thus the direct observation method was used for the analysis of posture and it was noted that the forward bending posture was the dominant posture in potato cultivation jobs. The workers engaged in tunneling jobs were compelled to adopt forward bending posture throughout the work time. In case of potato plantation and potato harvesting jobs the workers were also spend maximum time in forward bending posture. The workers were found to twist and bend their body frequently during potato plantation and potato harvesting jobs. The prolonged forward bending posture imposes a high static muscular load, particularly in the trunk region. So, forward bending posture in different phases of potato cultivation jobs was generally stressful to the musculoskeletal structures, including the vertebral column. This is consistent with the past studies that have shown that forward bending and twisting of the back impose higher postural strain than the straight back postures which are important risk factors for origin of discomfort [22-24]. Meyers et al. [25] showed the relation between stressful work postures and functional disturbance of pain in various parts of the musculoskeletal system. The workers usually required moving forward (sometimes sideways) under squat posture and such movements were strenuous and cumbersome.

The work-rest cycle is dichotomized into work and rest periods. The human body shows a rhythmic balance between energy consumption and energy replacement during work and rest peri- ods. This dual process is an integral part of the operation of muscles, of the heart and if we take all the biological functions into account of the organism as a whole. Work rest is, therefore, indispensable as a physiological requirement if performance and efficiency are to be maintained.

From the studies of work-rest patterns of the potato cultivators, it has been found that total duration of work shift was high (approximately 9 hours) in all jobs of potato cultivation. Thus the prolonged tasks performed in awkward posture (bend posture) may be possible causes of pain at different segments of the workers. Al-Rahamneh et al. [26] also point out in their studies that prolonged tasks have been positively associated with body part discomfort. According to Caicoyal and Delclos [27], those performing highly repetitive tasks for longer duration reported pain at different segments of their body.

Study of MSD and body discomfort revealed that the incidence of MSDs or pain was comparatively higher in tunneling job than that the workers engaged in potato plantation and potato harvesting jobs. However, lower back problem was found extremely prevalent in all types of job of potato cultivation. It was the highest in potato harvesting (98.08\%) followed by tunneling job $(96.67 \%)$ and potato plantation operation (84.31\%). Upper back problem was also prevalent in all types of tasks of potato cultivation. It was the highest in tunneling job $(75.0 \%)$ followed by potato harvesting $(73.08 \%)$ and seed plantation operation $(41.18 \%)$. Usually the workers of different potato cultivation jobs, adopt forward bending posture with frequent postural change and sometimes twisting posture also. Highest degree of pain / discomfort was observed in lumber region of the workers of all categories. This problem might be attributed to the prolonged forward bending and twisting postures with frequent postural change. Kothiyal and Yuen, [24]; Olendorf and Drury, [28] and Reneman et al. [29] strongly pointed that forward bending and twisting posture imposes higher postural strain among the workers which might be the cause of discomfort in different body parts $[23,30]$. Osborne et al. [31] studied on farmers and reported that lower back pain was the most common MSD among the farmers, followed by upper and then lower extremity MSDs. They also suggested that the prevalence of MSDs in farmers was greater than in non-farmer populations. Long term adoption of forward bending and twist posture was associated with postural stress. Investigation suggested that bending and twisting of back awkwardly and working in the same position were both significantly associated with prevalence of lower back problem $[9,32-34]$ and both were judged by workers to be the most problematic job factors contributing to pain and injury. Goldsheyder et al. [35] reported that there was a significant association of awkward postures with back pain and the prevalence of lower back problems was significantly increased with work tasks described as "bending or twisting back in an awkward way". Das and Gangopadhyay [3] studied on potato cultivators and reported that prolonged work activity, high repetitiveness and remaining constantly in an awkward posture for a prolonged period of time may lead to MSDs.

According to the report of NIOSH [36], the kneeling, squatting and non-neutral trunk postures are the awkward posture, which are responsible for lower back disorder. The National Research 
Council (NRC) and Institute of Medicine [37] also reported that there is a clear relationship between back disorders and physical load. The lower back pain (LBP) was commonly associated with decrease muscular strength, spinal flexibility, incapacity and eventually activity limitation due to sick leave and corresponding high costs to the society, which also reported by Van Tulder et al. [38].

The higher prevalence of work related MSD at different segments of the body of the workers might be due to use of significant force, repetitive movements and longer duration of exposure [23]. A constant repetition of movements imposes a cumulative work load which can cause pain and weakness and impaired function of the muscles and other soft tissues [39]. The physiologic problems that arise from repetitive work or overuse of certain muscles, tendons and soft-tissue structures have been addressed in terms of muscle fatigue, tissue density changes, and tissue strain [40]. Physiologic evidence shows that the rate and degree of tissue damage depends on the amount of force, repetition and duration of exposure [41]. The results also indicated that MSDs was prevalent in different parts of upper limbs. It was also revealed that most of the workers of three different potato cultivation tasks reported disorders in wrist and shoulder. Wrist problem was highest in potato plantation operation $(66.67 \%)$ followed by potato harvesting $(65.38 \%)$ and tunneling job (50.0\%). However, Disorder in the shoulder was highest in tunneling job (63.33\%) followed by potato harvesting $(51.92 \%)$ and seed plantation operation $(23.53 \%)$. All these potato cultivation tasks required frequent movement of the shoulder, but the frequency of movement was very high in case of tunneling job due to spade operation. In case potato harvesting job, they collect potato and load the collected potato in a basket and the workers had to lift the loaded basket to the head of the carrier in a regular interval. Thus the frequency of upper arm movement was very high and this might be the reason for the occurrence of shoulder pain of the workers. This may evoke shoulder muscular tenderness disorder. This is due to the static fatigue of the Trapezius muscle and multifactorial identification, including static and awkward posture and work practices [42]. In all those potato cultivation tasks, major percentages of workers were affected bilaterally. This might be due to the fact that in all operations the workers were using both right and left arms almost equally during performing the job.

The occurrence of MSDs exhibited variation in the subjects of different work experienced groups. The occurrence of MSDs was higher in the subjects of Gr.-A and Gr.-C than the Gr.-B. The higher prevalence of MSD in the workers of $\mathrm{Gr}$. -A might be due to lesser experience and skill. As the workers were newly recruited they were untrained and possessed a little knowledge to operate the hand tools. From the study of the Häkkänen et al. [43] it has been revealed that among trailer assembly workers a higher rate of sick leave due to disorders of the upper limbs was found for new workers compared with experienced ones. The higher incidence of MSDs in the workers of Gr.-C might be due to reduced muscle strength and endurance with the advancement of age [44]. Alexopoulos et al. [45]; Guo et al [46] and Habib et al.
[47] noted in their studies that MSDs was significantly increased with age.

The potato cultivators were compelled to adopt in different awkward postures for prolonged period while performing different jobs of potato cultivation. Ergonomic assessment of work postures is one of the starting points to address the problem of work related body pain. Researcher proposed different methods for ergonomic assessment of working posture and quantification of ergonomic risk factors. In the present study, different postures adopted by the cultivators while performing different tasks of potato cultivation were analyzed by OWAS, REBA and QEC methods. From the results of posture analysis of three jobs of potato cultivation, it was revealed that all postures adopted by the workers during potato cultivation jobs has been categorized as moderate to very high risk and this posture was needed corrective measure immediately.

According to the different posture analysis methods, the postures adopted by the male cultivators have been categorized as having 'moderate' to 'very high' risk levels in different tasks of potato cultivation. The workers suffered account of health problems, perhaps because of prolonged working hours, awkward posture and used less safety measures while working. The prevalence of MSDs also exhibited variation in the subjects having different work experience. Moreover, ergonomic interventions such as modifying work-rest schedules would improve the work conditions and postures of the male cultivators and reduce their MSDs. From this study it has been recommended that workers should avoid awkward work postures as far as possible and take adequate rest during their work for reducing job related health hazards. The strenuous posture is one of the major problems in potato cultivation jobs. This problem may be solved by devising new equipment, which can relieve them from adopting harmful bend postures. Avoiding loads during acute pain and performing some special types of exercises can reduce the low back pain. Awareness and training programs about the correct work posture, personal protective devices and using proper work methods among the cultivators may be another solution of the problem.

\section{References}

1. Census of India 2011. http://www.censusindia.gov.in

2. Gangopadhyay S, Das B, Das T, Ghoshal G. An ergonomic study on posture-related discomfort among preadolescent agricultural workers of West Bengal, India. International Journal of Occupational Safety and Ergonomics 2005, 11 (3): 315-322.

3. Das B, Gangopadhyay S. Prevalence of musculoskeletal disorders and physiological stress among adult male potato cultivators of West Bengal, India. Asia Pac J Public Health 2012. Jan 13. PMID: 22247108 [in press]

4. Sabharwal K and Kaushik S. Inter gender occupational health problems in Paddy cultivation. J Dairying Foods and HS 2011, 30(1): 43- 47. 
5. Das B, Gangopadhyay S. An ergonomics evaluation of posture related discomfort and occupational health problems among rice farmers. Occupational Ergonomics 2011, 10(12): 25-38.

6. Kar SK, Sau SK, Ahmed QR, Dhara PC. Ergonomic evaluation of work-rest pattern and work component of different rice cultivation tasks. The Indian Journal of Bio Research 2010, 79(3): 243-254.

7. Nag PK and Nag A. Drudgery, accidents and injuries in Indian agriculture. Industrial Health 2004, 42:149-162.

8. Kar SK and Dhara PC. An evaluation of musculoskeletal disorder and socioeconomic status of farmers in West Bengal, India. Nepal Medical College Journal 2007, 9(4): 245249.

9. Goswami S, Pal A, Dhara PC. Evaluation of work related musculoskeletal disorder and postural stress among female cultivators engaged in post harvesting tasks, Indian Journal of Biological Science 2012, 18:16-25.

10. Ermakova SV, Podstavkina TP, Strokina AN. Anthropometric atlas, recommendation on methods. Amerind Publishing Co. Pvt. Ltd., New Delhi. 1985.

11. Wilson JR and Corlette EN. Evaluation of human work a practical ergonomics methodology. Taylor and Francis, London. 1985.

12. Kuorinka I, Jonson B, Kilbom A, Vinterberg $H$, BieringSorenson F, Anderson G, et al. Standardized Nordic questionnaire for the analysis of musculoskeletal symptoms. Applied Ergonomics 1987, 18: 233-237.

13. Jacquelin LR, Drury G, Richard LB. A field methodology for the control of musculoskeletal injuries. Applied Ergonomics 1994, 25:3-16.

14. Kee D and Karwowski W. A Comparison of Three Observational Techniques for Assessing Postural Loads in Industry. International Journal of Occupational Safety and Ergonomics 2007, 13(1): 3-14.

15. Heinsalmi P. Method to measure working posture loads at working sites (OWAS). In: The Ergonomics of Working Postures. Corlette, Wilson and Manenica (Ed). Taylor and Francis, London. 1986, 100-104.

16. Hignett $S$ and McAtamney L. Rapid Entire Body Assessment (REBA). Applied Ergonomics 2000, 31: 201-205.

17. Li $G$ and Buckle P. Evaluating change in exposure to risk for musculoskeletal disorders - a practical tool. Suffolk, HSE Books CRR251. 1999.

18. Corlett EN. Pain, posture and performance. In: E.N. Corlett and J. Richardson (eds), Stress, Work Design and productivity, Wiley, London. 1981, pp 1-8.

19. Mc Atamney $L$ and Corlett EN. RULA: a survey method for the investigation of work related upper limb disorder. Applied Ergonomics 1993, 24(2): 91-99.

20. Keyserling WM. Postural analysis of the trunk and shoulders in simulated real time. Ergonomics 1986, 29:569-583.

21. Looze MP, Toussaint de, Ensink HM, Mangnus J, Beek C, Vander AJ. The validity of visual observation to assess posture in a laboratory-simulated, material handling task. Ergonomics 1994, 37:1335-1343.

22. Drake JD and Callaghan JP. Do flexion/extension postures affect the in vivo passive lumbar spine response to applied axial twist moments? Clin Biomech (Bristol, Avon) 2008, 23 (5): 510-9.

23. Chaffin DB, Andersson GBJ, Martin BJ. Occupational Biomechanics, fourth edition, Wiley-Interscience, New York. 2006.

24. Kothiyal K and Yuen TW. Muscle strain and perceived exertion in patient handling with and without a transferring aid. Occupational Ergonomics 2004, 4(3): 185-197.

25. Meyers JM, Miles JA, Faucett J, Janowitz I, Tejeda DG, Weber E, et al. Priority risk factors for back injury in agricultural field work: vineyard Ergonomics. Journal of Agromedicine 2001, 8: 37-52.

26. Al-Rahamneh HQ, Faulkner JA, Byrne C, Eston RG. Relationship between perceived exertion and physiologic markers during arm exercise with able-bodied participants and participants with poliomyelitis. Arch Phys Med Rehabil 2010, 91(2): 273-7.

27. Caicoyal M and Delclos GL. Work demands and musculoskeletal disorders from the Spanish National Survey. Occupational Medicine 2010, 60: 447-450.

28. Olendorf MR and Drury CG. Postural discomfort and perceived exertion in standardized box-holding postures. Ergonomics 2001, 44(15):1341-1367.

29. Reneman MF, Bults MMWE, Engbers LH, Mulders KKG, Göeken LNH. Measuring Maximum Holding Times and Perception of Static Elevated Work and Forward Bending in Healthy Young Adults. Journal of Occupational Rehabilitation 2001, 11(2): 87-97.

30. Granata KP and Marras WS. Relation between spinal load factors and the high-risk probability of occupational lowback disorder. Ergonomics 1999, 42:1187-1199.

31. Osborne A, Blaken C, Fullen BM, Meredith D, Phelan J, Mc Namara J, et al. Prevalence of musculoskeletal disorders among farmers: A systematic review. Am J Ind Med 2012, 55(2):143-158.

32. Roffey DM, Wai EK, Bishop P, Kwon BKS. Dagenais. Causal assessment of awkward occupational postures and low back pain: results of a systematic review. Spine 2010, 10(1): 89-99.

33. Merlino LA, Rosecrance JC, Anton D, Cook TM. Symptoms of musculoskeletal disorders among apprentice construction workers. Appl Occup Environ Hyg 2003, 18(1):57-64.

34. Pal A, De S, Sengupta P, Maity P, Dhara PC. Evaluation of work related musculoskeletal disorder and postural stress among female potato cultivators in West Bengal, India. Ergonomice SA 2015. (In sprees) 


\section{Original Article / IJOSH/ ISSN 2091-0878}

35. Goldsheyder D, Nordin M, Schecter S, Hiebert WR. Musculoskeletal symptom survey among mason tenders. Am J Ind Med 2002, 42: 384-396.

36. NIOSH. Musculoskeletal disorders and workplace factors: A critical review of epidemiologic evidence for work-related musculoskeletal disorders of the neck, upper extremity, and low back. Publication No. 97-141, 1997. Cincinnati: DHHS $\mathrm{NIOSH}$.

37. NRC and Institute of Medicine. Musculoskeletal Disorders and the Workplace: Low Back and Upper Extremities, In P. o. M. D. a. t. Workplace., (Ed.) Commission on Behavioral and Social Sciences and Education. National Academy Press; Washington, D.C. 2001.

38. Van Tulder MW, Koes BW, Bouter LM. A cost-of-illness study of back pain in the Netherlands. Pain 1995, 62:23340.

39. Gangopadhyay S, Ghosh T, Das T, Ghoshal G, Das BB. Prevalence of upper limb musculoskeletal disorders among brass metal workers in West Bengal, India. Industrial Health 2007, 45:365-370.

40. Valachi B and Valachi K. Mechanisms leading to musculoskeletal disorders in dentistry. J Am Dent Assoc 2003, 134 (10):1344-1350.

41. Geronilla KB, Miller GR, Mowrey KF, Wu JZ, Kashon ML, Brumbaugh K. et al. Dynamic force responses of skeletal muscle during stretch shortening cycle. Euro J Appl Physiol 2003, 90(1-2):144-153.

42. Hayes M, Cockrell D, Smith DR. A systematic review of musculoskeletal disorders among dental professionals. Int J Dent Hyg 2009, 7(3):159-65.

43. Häkkänen M, Viikari-Juntura E and Martikainen R. Job experience, work load, and risk of musculoskeletal disorders. Occup Environ Med 2001, 58:129-135.

44. Holmström E and Engholm G. Musculoskeletal disorders in relation to age and occupation in Swedish construction workers. Am J Ind Med 2003, 44(4):377-384.

45. Alexopoulos EC, Burdorf A, Kalokerinou A. Risk factors for musculoskeletal disorders among nursing personnel in Greek hospitals. International Archives of Occupational and Environmental Health 2003,76(4):289-294.

46. Guo HR, Chang YC, Yeh WY, Chen CW, Guo YL. Prevalence of musculoskeletal disorder among workers in Taiwan: A nationwide study. Journal of Occupational Health 2004, 46 (1): 26-36.

47. Habib RR, Hamdan M, Nuwayhid I, Odaymat F. Musculoskeletal Disorders among Full-Time Homemakers in Poor Communities. Women Health 2005, 42(2): 1-14. 